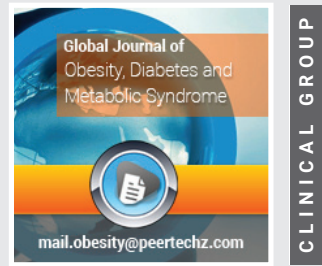

\title{
Remission of type 2 diabetes
}

\section{in a young, hypogonadal man \\ under long-term testosterone}

therapy: A case report

\section{George Mskhalaya ${ }^{1 *}$, Yulia Tishova ${ }^{2}$, Anas Alfaradzh ${ }^{3}$ and Svetlana Kalinchenko ${ }^{4}$}

\author{
${ }^{1}$ Department of Internal medicine, European Medical Center, Moscow, Russian Federation \\ 2Department of Endocrinology, Medical Center "K-Medicine”, Moscow, Russia Federation \\ ${ }^{3}$ Department of Internal medicine, European Medical Center, Moscow, Russian Federation \\ ${ }^{4}$ Clinical Endocrinology, Peoples' Friendship University of Russia, Moscow, Russian Federation
}

Received: 29 April, 2020

Accepted: 04 June, 2020

Published: 05 June, 2020

*Corresponding author: George Mskhalaya,

Department of Internal medicine, European Medical Center, Moscow, Russian Federation,

E-mail:mskhalaya@mail.ru

Keywords: Hypogonadism; Testosterone therapy; Type 2 diabetes; Remission; Erectile dysfunction

https://www.peertechz.com

Check for updates

\begin{abstract}
Background: The increasing prevalence of obesity, in particular in young patients, represents a growing clinical and health-care cost problem. Young adulthood obesity strongly increases the risk of type 2 diabetes (T2DM), hypertension, myocardial infarction, stroke or venous thromboembolism. Young obese T2DM men have a high prevalence of low testosterone concentrations indicating eugonadotropic hypogonadism. An existing but undetected testosterone deficiency will substantially hamper weight loss or render it impossible. In such cases, returning the testosterone level to normal range is therefore the necessary pre-condition to fight obesity and thus the related comorbidities.
\end{abstract}

Case presentation: A 20-year-old man with grade III obesity complained of fatigue, dry mouth, and erectile dysfunction (ED). Medical examination revealed uncontrolled T2DM, pronounced dyslipidemia, severe vitamin D deficiency, and a remarkably low testosterone level. Medication with metformin and vitamin D was initiated and testosterone therapy (TTh) was started. Under TTh, the patient continuously lost weight, and his blood sugar and lipid profile progressively normalized. Finally, a complete remission of T2DM was reached and all baseline complaints including ED were fully gone. Even after TTh was stopped, all respective values remained in the normal range.

Conclusions: We conclude that TTh worked as a necessary stimulus along with standard therapy for consequential facilitation of weight reduction and associated recovery of the body's own production of testosterone in particular in terms of a complete remission of T2DM.

\section{Abbreviations}

BMI: Body Mass Index; ED: Erectile Dysfunction; T2DM: Type 2 Diabetes Mellitus; TTh: Testosterone Therapy

\section{Background}

The increasing incidence of obesity in younger populations constitutes a serious problem both in terms of personal health and resulting health-care costs. Young adulthood obesity strongly increases the risk of T2DM, hypertension, myocardial infarction, stroke or venous thromboembolism [1]. Young T2DM men, in particular in combination with overweight or obesity, have a very high prevalence ( $>50 \%$ ) of low testosterone concentrations indicating eugonadotropic hypogonadism [2,3]. Testosterone deficiency disturbs physiological processes such as muscle and bone formation and promotes further fat mass gain. Moreover, lack of testosterone negatively impacts sexual function and reproductive capacity during the young patients' peak reproductive years.

For young obese men, the combination of T2DM and hypogonadism means a profound health burden and a loss in quality of life. Left untreated, the risk is manifested to develop life-threatening diseases. Thus, an appropriate treatment at an early stage is of utmost importance. 
In this report we present a case of a young type 2 diabetic man with low testosterone level who benefitted from TTh in terms of considerable weight loss and complete remission of T2DM.

\section{Case presentation}

A 20-year-old man presented to a specialist for endocrinology and andrology with complaints of fatigue, dry mouth, and ED. The patient showed class III obesity with a body mass index (BMI) of $44.2 \mathrm{~kg} / \mathrm{m}^{2}$ (height: $183 \mathrm{~cm}$; weight: 148 $\mathrm{kg}$; waist circumference: $137 \mathrm{~cm}$ ). The patient tried to decrease his weight under the supervision of a nutritionist at the age of 18 , lost $17 \mathrm{~kg}$ during 5 months, but then gained back $25 \mathrm{~kg}$ during 1.5 years. The elevated blood sugar level $\left(\mathrm{HbA}_{1 \mathrm{c}}: 7.6 \%\right.$; fasting blood glucose: $9.3 \mathrm{mmol} / \mathrm{L}$ ) indicated uncontrolled T2DM . The high triglyceride level (2.37 mmol/L), borderline high low density cholesterol (LDL) and critical low high density cholesterol (HDL) value marked a pronounced dyslipidemia (LDL: $3.65 \mathrm{mmol} / \mathrm{L}$; HDL: $0.79 \mathrm{mmol} / \mathrm{L}$; LDL/HDL ratio 4.62). Blood analysis revealed a remarkably low total testosterone level of $5.42 \mathrm{nmol} / \mathrm{L}$ and SHBG of $14.1 \mathrm{nmol} / \mathrm{L}$; by calculation, free testosterone resulted as $152 \mathrm{pmol} / \mathrm{L}$. A severe vitamin D deficiency was noted ( $4.0 \mathrm{ng} / \mathrm{mL})$. $\mathrm{LH}$, prolactin and TSH levels were within normal range. Fasting blood samples before $11 \mathrm{am}$ were collected to measure circulating biomarkers of metabolic health and hormones. Possible reasons for low testosterone level were: obesity, DM type 2 with high sugar levels, vitamin D deficiency. A moderate energy restriction (non-ketogenic diet supplying $100-150 \mathrm{~g}$ carbohydrate/day) of $25 \%$ to $35 \%$ relative to estimated energy expenditure was recommended. The patient was encouraged to increase physical activity according to the global recommendations from the World Health Organization (WHO) [4] of $150 \mathrm{~min}$ of moderate-intensity aerobic physical activity throughout the week [World Health Organization. Physical Activity and Adults].

Medications were initiated with metformin (1,000 mg twice a day) and vitamin D 10,000 IU per day. TTh was started with depot injections of testosterone undecanoate $1,000 \mathrm{mg}$ (injected i.m. every three months following an initial 6 -week interval). The patient was examined on a regular basis throughout the observation period of 42 months.

Right after the first injection, the testosterone level returned to normal and remained in the normal range onward (Figure 1).

Under TTh, body weight and waist circumference constantly decreased. After 12 months the original class III obesity was reduced to overweight and BMI remained below $30 \mathrm{~kg} / \mathrm{m}^{2}$ onward (Figures 2-4). $\mathrm{HbA}_{1 \mathrm{c}}$ decreased to $5.7 \%$ in month 3 and remained well below this value further on (Figure 5). The lipid profile returned to normal in month 6 and remained in the normal range onwards (triglycerides below $1.6 \mathrm{mmol} / \mathrm{L}$; LDL/ HDL ratio below 3) (Figures 6,7). The International Index of Erectile Function (IIEF-5) as diagnostic tool for ED [5] revealed a considerable improvement from mild to moderate ED at baseline to mild in month 3 and no ED from month 6 onward.
The health-related quality of life resulting from physical, sexual, and mental well-being was measured with the Aging Males' Symptoms scale (AMS) [6] and showed a remarkable improvement from score 51 (severe symptoms) at baseline to less than 26 (no symptoms) from month 6 onward.

Resulting from the normalization of blood sugar, lipid profile, and vitamin D level, medication with metformin could be stopped in month 12 and vitamin D dose was halved to 5,000 IU/day. In month 20, overweight was achieved and testosterone therapy was stopped. Nevertheless, values for total testosterone as well as blood sugar and lipid profile remained constant in the normal range during the 19 months observation period following termination of TTh. Ten months after terminating testosterone treatment, the patient got married and his wife got pregnant three months later.

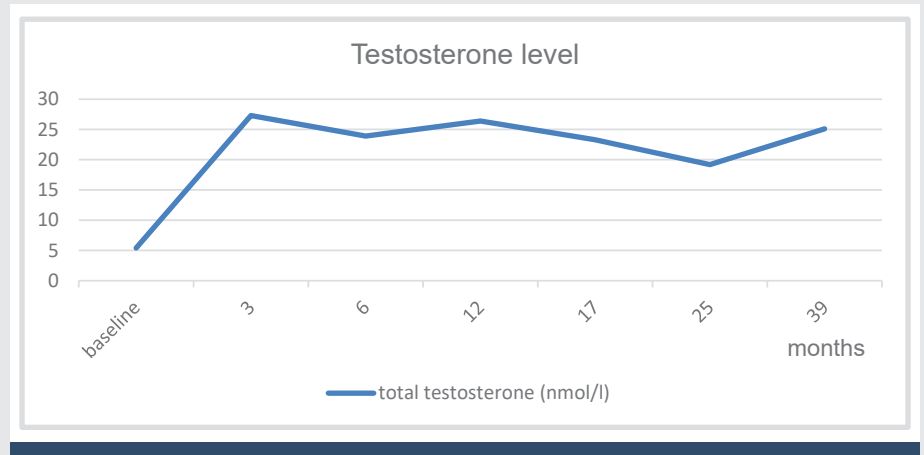

Figure 1: Total testosterone normalized under TTh.

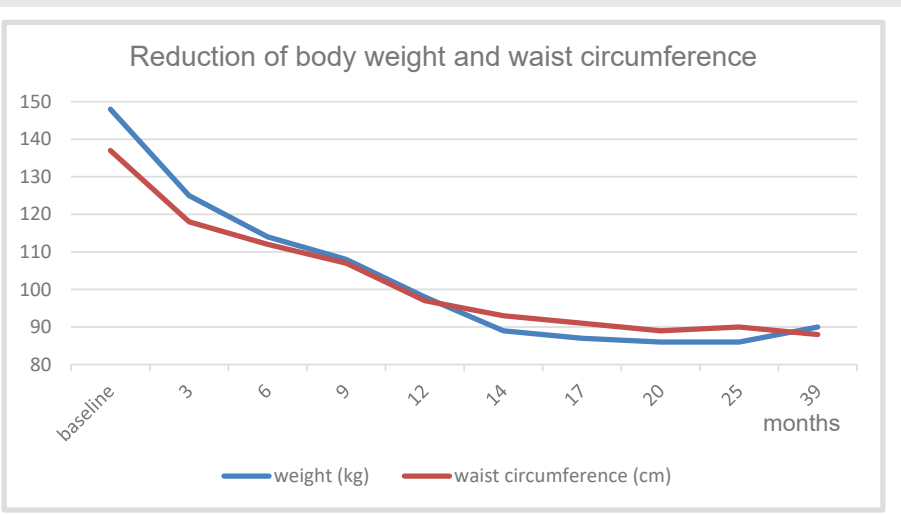

Figure 2: Under TTh, body weight and waist circumference normalized; BMI decreased from grade III obesity $\left(44 \mathrm{~kg} / \mathrm{m}^{2}\right)$ to overweight $\left(27 \mathrm{~kg} / \mathrm{m}^{2}\right)$.

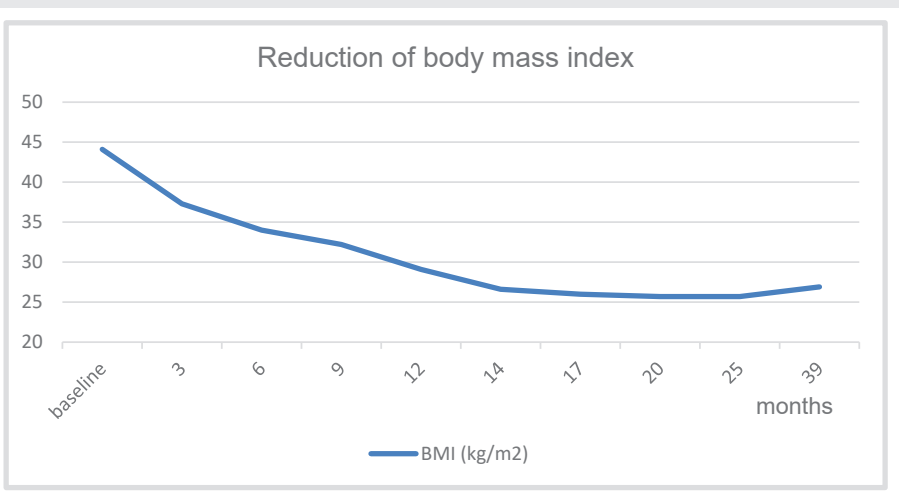

Figure 3: Under TTh body mass index improved substantially. 


\section{Discussion and conclusions}

At baseline, the patient had a remarkably low testosterone level. With total testosterone at $5.42 \mathrm{nmol} / \mathrm{L}$ and free testosterone at $152 \mathrm{pmol} / \mathrm{L}$, he showed values far below the lower limit of normal range of $12 \mathrm{nmol} / \mathrm{L}$ (total testosterone) and $243 \mathrm{pmol} / \mathrm{L}$ (free testosterone), respectively, as recommended by the European Association of Urology [7] and the International Society of Sexual Medicine [8]. Despite the relatively young age of the patient, $\mathrm{AMH}$-scale was used to determine the severity of hypogonadism symptoms, the AMS scale and the three subscales have good internal consistency and test-retest reliability [9]. Vitamin D deficiency is often correlated with hypogonadism, but causal relationship and

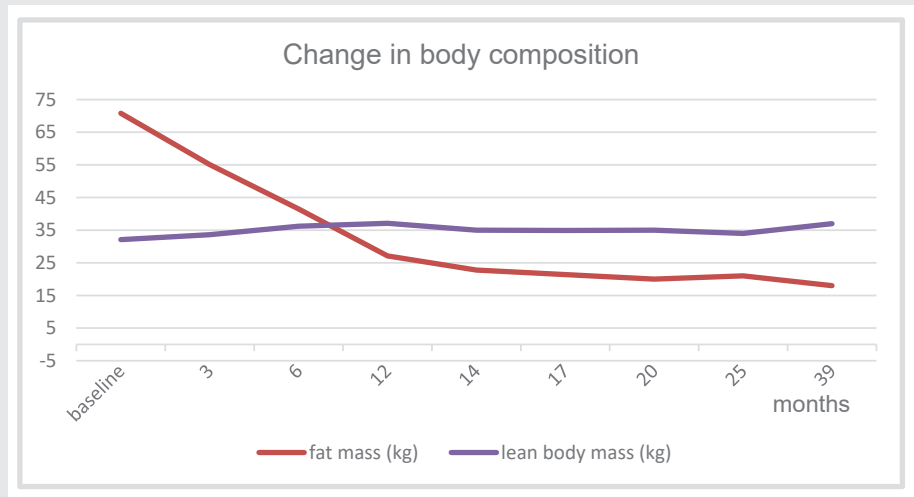

Figure 4: Under TTh body composition improved substantially.

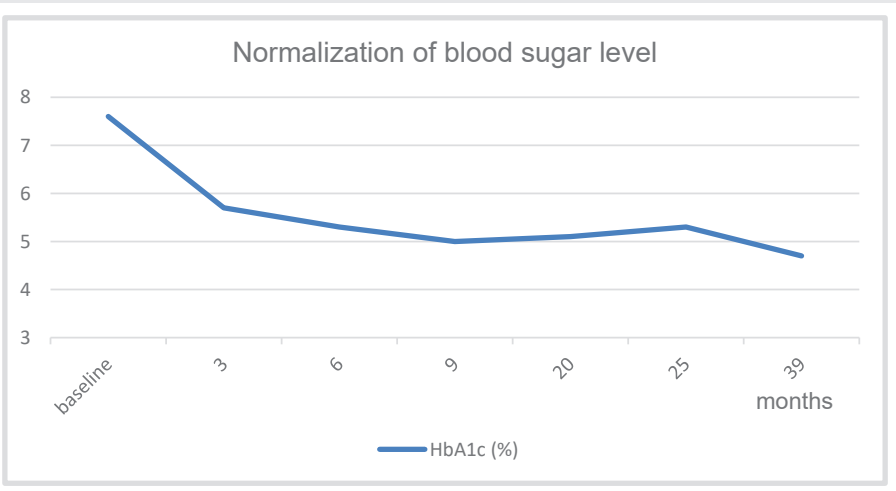

Figure 5: $\mathrm{HbA}_{1 \mathrm{c}}$ baseline values of $7.6 \%$ normalized to well below $5.7 \%$.

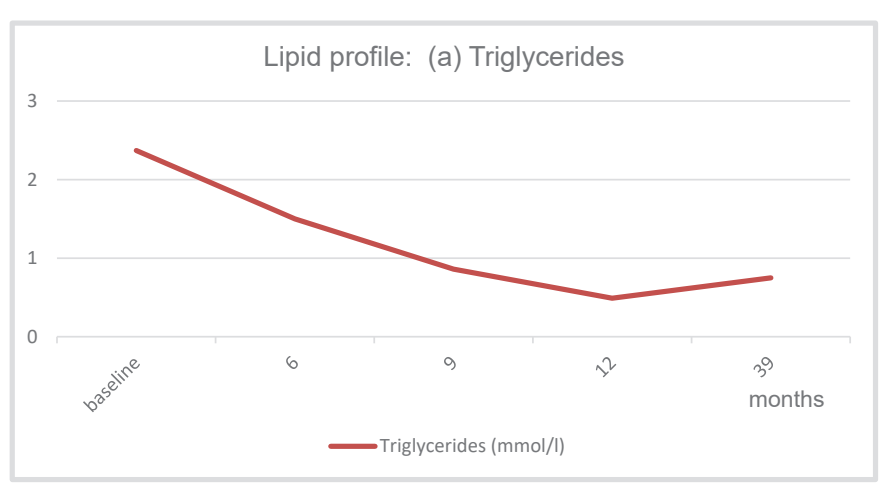

Figure 6: Triglycerides returned to normal range after month 3 and 6, resp., and remained in the normal range onwards.
Lipid profile: (b) HDL, LDL, and LDL/HDL ratio

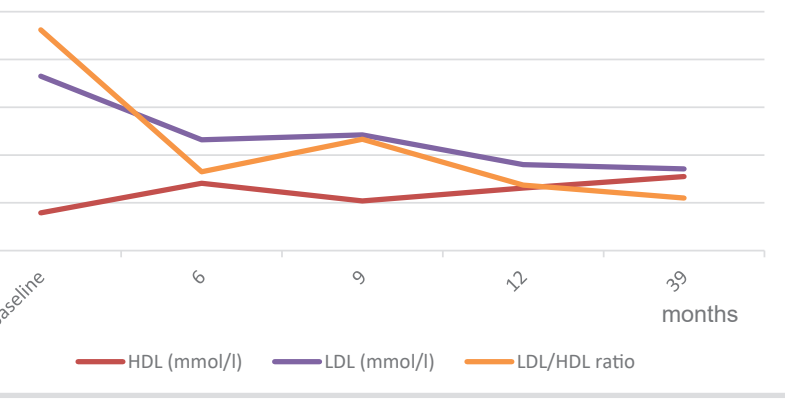

Figure 7: LDL/HDL ratio returned to normal range after month 3 and 6 , resp., and remained in the normal range onwards.

molecular mechanism are not yet clear [Trummer et al. 2018] [10]. Definitely, the combination of subnormal values of both testosterone and vitamin $\mathrm{D}$ is considered a marker of poor health and indicates a high risk for all-cause and cardiovascular mortality [11].

Under TTh the patient's testosterone level normalized quickly (Figure 1). Regular vitamin D administration compensated the original vitamin insufficiency and may have supported the recovery of endogenous testosterone production.

The 20-year-old patient presented here was not just obese but had very severe class III obesity at a very young age. So not only the existing impact of obesity but also the threatening consequences of long-term obesity required effective actions.

Diet and physical activity are key recommendations for obese patients, but it is a well-known fact that in most cases patients do not succeed in achieving effective and sustained weight reduction [12-16]. In a relatively recent meta-analysis serum testosterone level was significantly lower in patients with diabetes mellitus compared with those without, with a mean difference of $76.6 \mathrm{ng} / \mathrm{dL}$ and a significant correlation was found between low testosterone level and different components of metabolic syndrome, even after adjusting for age, BMI, and race [17].

A possible reason for the difficulty in losing weight is a lack of testosterone as this plays a crucial role in several regulatory processes including fat reduction and increase in muscle mass. Thus, an existing but undetected testosterone deficiency will substantially hamper weight loss or render it impossible. In these cases, restoring testosterone to the normal range is a pre-condition to successfully fight obesity. Testosterone may play a role in reducing pro-inflammatory cytokines in vitro and in vivo, increasing insulin sensitivity in both muscle and adipose tissue and promoting catecholamine-induced lipolysis [18-21]. Recent study showed that long-term TTh may prevent prediabetes progression to $\mathrm{T} 2 \mathrm{D}$ in men with hypogonadism, improve glycemic and lipid metabolism [22].

Under TTh the patient continuously lost weight and baseline class III obesity (BMI $44 \mathrm{~kg} / \mathrm{m}^{2}$ ) was reduced to overweight $\left(\mathrm{BMI}<30 \mathrm{~kg} / \mathrm{m}^{2}\right.$ ) (Figure 3). This effect of TTh has also been shown in a number of long-term studies with observation 
periods of up to eight years with obese hypogonadal men achieving a significant and sustained weight reduction under TTh [23,24]. The weight reduction due to normalization of testosterone level does not only refer to the reduction of body fat but also comprises an increase of lean body mass which refers primarily to muscle mass $[25,26]$. In a recent metaanalysis study (59 trials included enrolling more than 5,000 patients) testosterone therapy was associated with a significant reduction in fat and with an increase in lean mass as well as with a reduction of fasting glycaemia and insulin resistance [Corona 2015] [27]. In other words, getting testosterone back to normal range does not only mean to reduce body weight but also to improve body composition. This considerable improvement was also documented for the patient presented here.

Metformin use clearly played a great role in decreasing and maintaining normal blood sugar levels and reducing basal hyperinsulinemia. The combination of physical exercise, metformin, calorie restriction and normalization of testosterone level were associated with a substantial change in body composition, i.e. significant loss of fat mass with simultaneous increase in lean body mass (Figures 3, 4).

At baseline, the patient was diagnosed with T2DM. In particular taking into account his very young age, this meant a serious diagnosis in view of a possible lifelong condition which usually gets worse over time and its inherent high risk of developing sequential illnesses and complications. Furthermore, evidence is emerging that young-onset T2DM is of a more aggressive disease phenotype than late-onset T2DM leading to premature development of complications and increased comorbidities, serious adverse effects and, consequently, reduced life expectancy $[28,29]$. Thus, management of T2DM is of utmost importance in particular for a young patient.

Under TTh, and strongly linked to the patient's weight loss achieved under TTh, the blood sugar level normalized and the diabetes went into remission. It is noteworthy that $\mathrm{HbA}_{1 \mathrm{c}}$ values remained in the normal range even after metformin was discontinued, i.e. the remission was stable during the following 29 months observation time without any T2DM medication.

In summary, the baseline condition of the very young, obese, hypogonadal patient presented here can be described as poor health with serious risk factors to develop chronic and life-threatening diseases. Under TTh along with metformin therapy, low calorie diet, physical exercise, vitamin D supplementation the patient recovered completely . Even after discontinuation of TTh, the patient's testosterone level remained within the normal range during the following observation period of 19 months. Also his blood sugar values and lipid profile remained within the normal limits and he did not regain weight. We conclude that TTh worked as a necessary stimulus along with standard therapy for consequential facilitation of weight reduction and associated recovery of the body's own production of testosterone in particular in terms of a complete remission of T2DM.

\section{References}

1. Schmidt $M$, Johannesdottir $S A$, Lemeshow $S$, Lash $T L$, Ulrichsen $S P$, et al. (2013) Obesity in young men, and individual and combined risks of type 2 diabetes, cardiovascular morbidity and death before 55 years of age: a Danish 33-year follow-up study. BMJ Open. Link: https://bit.ly/301hJhg

2. Mogri M, Dhindsa S, Quattrin T, Ghanim H, Dandona P (2013) Testosterone concentrations in young pubertal and post-pubertal obese males. Clin Endocrinol 78: 593-599. Link: https://bit.ly/2Y2GPtk

3. Chandel A, Dhindsa S, Topiwala S, Chaudhuri A, Dandona P (2008) Testosterone concentrations in young patients with diabetes. Diabetes Care 31: 2013-2017. Link: https://bit.ly/2z1xvgV

4. World Health Organization. Physical Activity and Adults - Recommended levels of physical activity for adults aged $18-64$ years. Link: https://bit.ly/3cxvXsS

5. Rosen RC, Riley A, Wagner G, Osterloh IH, Kirkpatrick J, et al. (1997) The International Index of Erectile Function (IIEF): A multidimensional scale for assessment of erectile dysfunction. Urology 49: 822-830. Link: https://bit.ly/2Xx3kaV

6. Heinemann LAJ, Zimmermann T, Vermeulen A, Thiel C (1999) A New 'Aging Male's Symptoms' (AMS) Rating Scale. The Aging Male 2: 105-114. Link: https://bit.ly/2zRZ110

7. Dohle GR, Arver S, Bettocchi C, Jones TH, Kliesch S (2018) EAU guidelines on male hypogonadism. Link: https://bit.ly/2U7IWLf

8. Dean JD, McMahon CG, Guay AT, Morgentaler A, Althof SE, et al. (2015) The International Society for Sexual Medicine's process of care for the assessment and management of testosterone deficiency in adult men. J Sex Med 12 1660-1686. Link: https://bit.ly/305X5N2

9. Trummer C, Pilz S, Schwetz V, Obermayer-Pietsch B, Lerchbaum E (2018) Vitamin D, PCOS and androgens in men: a systematic review. Endocr Connect 7: R95-R113. Link: https://bit.ly/2YcVIPB

10. Lee CP, Chiu YW, Chu CL, Chen Y, Jiang KH, et al. (2016) A reliability generalization meta-analysis of coefficient alpha and test-retest coefficient for the aging males' symptoms (AMS) scale. Aging Male 19: 244-253. Link: https://bit.ly/3dvFH8

11. Lerchbaum E, Pilz S, Boehm BO, Grammer TB, Obermayer-Pietsch B, et al. (2012) Combination of low free testosterone and low vitamin D predicts mortality in older men referred for coronary angiography. Clin Endocrinol 77: 475-483. Link: https://bit.ly/3cpGs1i

12. Borg P, Kukkonen-Harjula K, Fogelholm M, Pasanen M (2002) Effects of walking or resistance training on weight loss maintenance in obese, middleaged men: a randomized trial. Int J Obes Relat Metab Disord 26: 676-683. Link: https://bit.ly/2UaBIGB

13. Fogelholm M, Kukkonen-Harjula K (2000) Does physical activity prevent weigh gain--a systematic review. Obes Rev 1: 95-111. Link: https://bit.ly/3dwZ297

14. Hursel R, Viechtbauer W, Westerterp-Plantenga MS (2009) The effects of green tea on weight loss and weight maintenance: a meta-analysis. Int $\mathrm{J}$ Obes (Lond) 33: 956-961. Link: https://go.nature.com/2MrFDuj

15. Claessens M, van Baak MA, Monsheimer S, Saris WH (2009) The effect of a low-fat, high-protein or high-carbohydrate ad libitum diet on weight loss maintenance and metabolic risk factors. Int J Obes (Lond). 33: 296-304. Link: https://bit.ly/2ACjiYp

16. Delbridge EA, Prendergast LA, Pritchard JE, Proietto J (2009) One-year weigh maintenance after significant weight loss in healthy overweight and obese subjects: does diet composition matter? Am J Clin Nutr 90: 1203-1214. Link: Link: https://bit.ly/374XUHh

Citation: Mskhalaya G, Tishova Y, Alfaradzh A, Kalinchenko S (2020) Remission of type 2 diabetes in a young, hypogonadal man under long-term testosterone therapy: A case report. Glob J Obes Diabetes Metab Syndr 7(2): 024-028. DOI: https://dx.doi.org/10.17352/2455-8583.000043 
17. Ding EL, Song Y, Malik VS, Liu S (2006) Sex differences of endogenous sex hormones and risk of type 2 diabetes: a systematic review and meta-analysis. JAMA 295: 1288-1299. Link: https://bit.ly/2Mvv6y0

18. Dhindsa S, Ghanim H, Batra M, Dandona P (2018) Hypogonadotropic hypogonadism in men with diabesity. Diabetes Care 41: 1516-1525. Link: https://bit.ly/3eLDuWs

19. Grossmann M (2018) Hypogonadism and male obesity: focus on unresolved questions. Clin Endocrinol (Oxf) 89: 11-21. Link: https://bit.ly/305Y140

20. Rastrelli G, Filippi S, Sforza A, Maggi M, Corona G, et al. (2018) Metabolic syndrome in male hypogonadism. Front Horm Res 49: 131-155. Link: https://bit.ly/2XujbH4

21. Gianatti EJ, Grossmann M (2020) Testosterone deficiency in men with Type 2 diabetes: pathophysiology and treatment. Diabet Med 37: 174-186. Link: https://bit.ly/3cwsvyC

22. Yassin A, Haider A, Haider K, Caliber M, Doros G, et al. (2019) Testosterone Therapy in Men With Hypogonadism Prevents Progression From Prediabetes to Type 2 Diabetes: Eight-Year Data From a Registry Study. Diabetes Care 42 1104-1111. Link: https://bit.ly/2U57K6z

23. Saad F, Yassin A, Doros G, Haider A (2016) Effects of long-term treatment with testosterone on weight and waist size in 411 hypogonadal men with obesity classes I-III: observational data from two registry studies. Int J Obes 40: 162 170. Link: https://bit.ly/30bHD1G
24. Francomano D, Ilacqua A, Bruzziches R, Lenzi A, Aversa A (2014) Effects of 5-year treatment with testosterone undecanoate on lower urinary tract symptoms in obese men with hypogonadism and metabolic syndrome. Urology 83: 167-173. Link: https://bit.ly/30i25ho

25. Svartberg J, Agledahl I, Figenschau Y, Sildnes T, Waterloo K, et al. (2008) Testosterone treatment in elderly men with subnormal testosterone levels improves body composition and BMD in the hip. Int J Impot Res 20: 378-387. Link: https://bit.ly/30al25R

26. Aversa A, Bruzziches R, Francomano D, Rosano G, Isidori AM, et al. (2010) Effects of testosterone undecanoate on cardiovascular risk factors and atherosclerosis in middle-aged men with late-onset hypogonadism and metabolic syndrome: results from a 24-month, randomized double-blind, placebo-controlled study. J Sex Med 7: 3495-3503. Link: https://bit.ly/2XAShO3

27. Corona G, Giagulli VA, Maseroli E, Vignozzi L, Aversa A, et al. (2016) Therapy of Endocrine Disease: Testosterone supplementation and body composition: results from a meta-analysis study. Eur J Endocrinol 174: R99-R116. Link: https://bit.ly/2Y121A9

28. Khang AR (2018) Letter: Clinical characteristics of people with newly diagnosed type 2 diabetes between 2015 and 2016: difference by age and body mass index. Diabetes Metab J 42: 249-250. Link: https://bit.ly/370eRTk

29. Lascar N, Brown J, Pattison H, Barnett AH, Bailey CJ, et al. (2018) Type diabetes in adolescents and young adults. Lancet Diabetes Endocrinol 6: 6980.Link: https://bit.ly/2A3xLfX

\section{Discover a bigger Impact and Visibility of your article publication with} Peertechz Publications

\section{Highlights}

* Signatory publisher of ORCID

* Signatory Publisher of DORA (San Francisco Declaration on Research Assessment)

* Articles archived in worlds' renowned service providers such as Portico, CNKI, AGRIS, TDNet, Base (Bielefeld University Library), CrossRef, Scilit, J-Gate etc.

* Journals indexed in ICMJE, SHERPA/ROMEO, Google Scholar etc.

* OAI-PMH (Open Archives Initiative Protocol for Metadata Harvesting)

* Dedicated Editorial Board for every journa

* Accurate and rapid peer-review process

* Increased citations of published articles through promotions

* Reduced timeline for article publication

Submit your articles and experience a new surge in publication services (https://www.peertechz.com/submission).

Peertechz journals wishes everlasting success in your every endeavours.

Copyright: (c) 2020 Mskhalaya G. This is an open-access article distributed under the terms of the Creative Commons Attribution License, which permits unrestricted use, distribution, and reproduction in any medium, provided the original author and source are credited.

Citation: Mskhalaya G, Tishova Y, Alfaradzh A, Kalinchenko S (2020) Remission of type 2 diabetes in a young, hypogonadal man under long-term testosterone therapy: A case report. Glob J Obes Diabetes Metab Syndr 7(2): 024-028. DOI: https://dx.doi.org/10.17352/2455-8583.000043 